\title{
Molecular Structure, Vibrational Spectral Studies, NLO Properties and frontier molecular investigations of 2-Chloro-6-Fluoro Benzaldehyde by DFT
}

\author{
S. K. Tyagi ${ }^{1}$, Sachin Kumar $^{2}$ \\ ${ }^{1}$ Associate Professor \& Head, Department of Physics, CSSS (PG) College, Machhra, Meerut \\ ${ }^{2}$ Associate Professor Head, Department of Physics, A.S (PG) College, Mawana, Meerut
}

\begin{abstract}
Article Info

Volume 8, Issue 6

Page Number : 481-483

\section{Publication Issue}

November-December-2021

\section{Article History}

Accepted : 15 Dec 2021

Published : 30 Dec 2021

Benzaldehyde and its derivatives are the simplest in aromatic aldehydes and have wide range of use in different industries. Due to this reason, there exist a vast field of study of substituted benzaldehydes. Quantum mechanical calculations of geometries, energies, vibrational wave numbers and thermodynamic constants have been performed with Gaussian 09 program package using the beece-3-Lee-Yang-Parr- (B3LYP) functional supplemented with the standard 6-31G (DP). The optimized geometrical parameters obtained by computational method used shows good agreement with the experimental data. The thermodynamic properties as heat capacity, entropy, enthalpy and Gibb's free energy of the titled compounds at different temperature were also calculated along with the dipole moment, Polarizability and hyperpolarizability.

Keywords :- 2-Chloro-6-fluoro benzaldehyde, NLO, Gaussian 09w DFT/B3LYP, thermodynamic parameters, dipole moment, polarizability, hyperpolarizability.
\end{abstract}

\section{INTRODUCTION}

Benzaldehyde is the simplest aromatic aldehyde and substitution of a functional group in benzaldehyde changes the spectra remarkably. Raman spectra of some substituted benzaldehydes have been recorded . Benzaldehyde is being used as a pesticide and also as an anti-cancerous and have shown anti-tumor activity in mice. $[1,2]$

The vibrational spectra of benzaldehyde and its derivatives have been extensively investigated by many early researchers. [3-6] In the present study quantum mechanical calculation of geometries, energies ware numbers and thermodynamic function of the compound have been performed. In this study we will investigate vibrational spectroscopic properties and other parameters of 2-Chloro-6-fluoro benzaldehyde, (hereafter referred as 2,6-CFB).

\section{COMPUTATIONAL}

All the calculation were carried out with Gaussian 09W program package [7] using the Beckle-3LeeYang-Parr (B3LYP) functional supplemented with the standard 6-31G(dp) basis set further referred as DFT 
calculations. All the parameters were allowed to relax and all the calculations converged to an optimized geometry which corresponds to a true energy minimum as revealed by the absence of imaginary values in the wave number calculations.

\section{RESULTS AND DISCUSSION}

Various physical and chemical properties of 2,6-CFB are as follows

\begin{tabular}{|l|l|l|}
\hline 1. & Molecular Formula & $\mathrm{C}_{7} \mathrm{H}_{4} \mathrm{ClFO}$ \\
\hline 2. & Molecular Weight & 158.56 \\
\hline 3. & Exact Mass & 157.9934706 \\
\hline 4. & Monoisotopic Mass & 157.9934706 \\
\hline 5. & $\begin{array}{l}\text { Topological Polar } \\
\text { Surface Area }\end{array}$ & $17.1 \AA$ \\
\hline 6. & Melting Point & $32-35^{\circ} \mathrm{C}$ \\
\hline 7. & Boiling Point & $92^{\circ} \mathrm{C}$ \\
\hline 8. & Density & $1.352 \mathrm{~g} / \mathrm{cm} 3$ \\
\hline 9. & Flash Point & $101^{\circ} \mathrm{C}$ \\
\hline 10. & Refractive Index & 1.559 \\
\hline & & \\
\hline
\end{tabular}

\section{A- Molecular Structure: -}

The molecular structure of the mentioned compound 2,6-CFB is shown in Figure-1. The optimized bond lengths bond angles dihedral angles of the compound is calculated by B3LYP method using B3LYP 6-311++ $\mathrm{G}(\mathrm{d})$ and 6-311+ + G(d,p) bases are listed in Table-1 and is in accordance with atom numbering scheme as shown in Fig-1. Since the exact crystal structure of the compound is not available, the optimized structure can only be compared with other similar system for which the crystal structures have been solved.

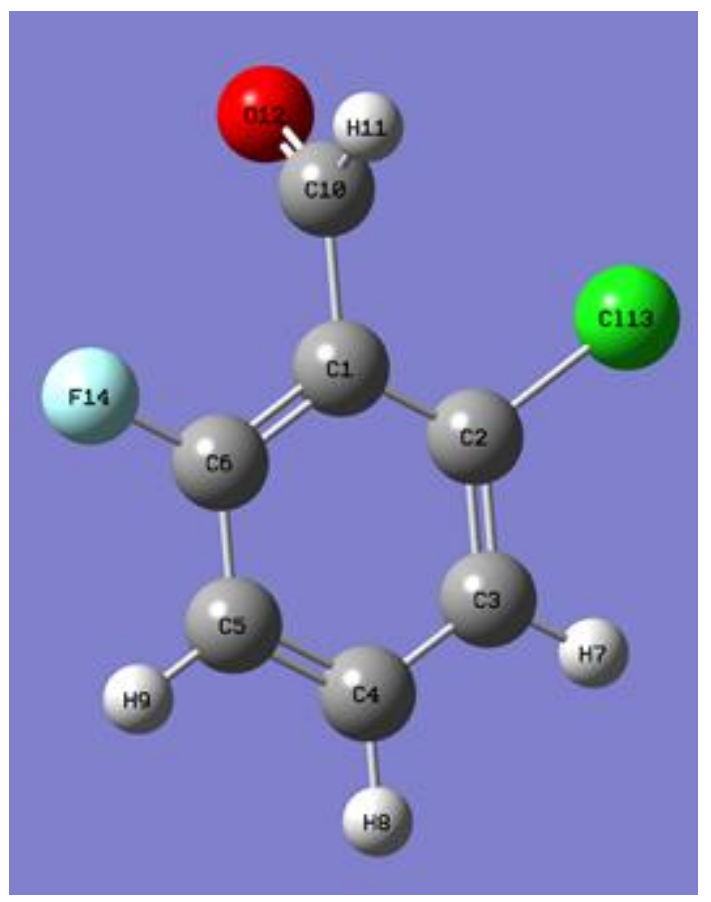

Fig-1 Molecular structure of 2,6-CFB

Table -1

Calculated Optimized Geometrical Parameters of 2,6-CFB at B3LYP/6-31G(d,p,) Bond length $\left(\mathrm{A}^{0}\right)$, Bond Angle $\left(^{0}\right)$, Dihedral Angle $\left(^{\circ}\right)$

\begin{tabular}{|c|c|c|c|c|c|}
\hline $\begin{array}{c}\text { Atoms Of } \\
\text { molecule }\end{array}$ & $\begin{array}{c}\text { Bond } \\
\text { length }\left(\mathrm{A}^{0}\right)\end{array}$ & $\begin{array}{c}\text { Angle } \\
\text { between } \\
\text { atoms }\end{array}$ & $\begin{array}{c}\text { Bond } \\
\text { Angle( }\left({ }^{\circ}\right)\end{array}$ & $\begin{array}{c}\text { Dihedral angle } \\
\text { between atoms }\end{array}$ & $\begin{array}{c}\text { Dihedral } \\
\text { angle( }\left({ }^{0}\right)\end{array}$ \\
\hline $\mathrm{R}(1,2)$ & 1.3952 & $\mathrm{~A}(2,1,6)$ & 119.9985 & $\mathrm{D}(6,1,2,3)$ & 0.0323 \\
\hline $\mathrm{R}(1,6)$ & 1.3948 & $\mathrm{~A}(2,1,10)$ & 119.9972 & $\mathrm{D}(6,1,2,13)$ & 179.9532 \\
\hline
\end{tabular}


S. K. Tyagi et al Int J Sci Res Sci \& Technol. November-December-2021, 8 (6) : 481-483

\begin{tabular}{|c|c|c|c|c|c|}
\hline $\mathrm{R}(1,10)$ & 1.54 & $\mathrm{~A}(6,1,10)$ & 120.0043 & $\mathrm{D}(10,1,2,3)$ & -179.9729 \\
\hline $\mathrm{R}(2,3)$ & 1.3947 & $\mathrm{~A}(1,2,3)$ & 120.0086 & $\mathrm{D}(10,1,2,13)$ & -0.052 \\
\hline $\mathrm{R}(2,13)$ & 1.76 & $\mathrm{~A}(1,2,13)$ & 119.9808 & $\mathrm{D}(2,1,6,5)$ & 0.0149 \\
\hline $\mathrm{R}(3,4)$ & 1.3954 & $\mathrm{~A}(3,2,13)$ & 120.00106 & $\mathrm{D}(2,1,6,14)$ & 179.9892 \\
\hline $\mathrm{R}(3,7)$ & 1.0997 & $\mathrm{~A}(2,3,4)$ & 119.9942 & $\mathrm{D}(10,1,6,5)$ & -179.9798 \\
\hline $\mathrm{R}(4,5)$ & 1.3948 & $\mathrm{~A}(2,3,7)$ & 120.0128 & $\mathrm{D}(10,1,6,14)$ & -0.056 \\
\hline $\mathrm{R}(4,8)$ & 1.0997 & $\mathrm{~A}(4,3,7)$ & 119.993 & $\mathrm{D}(2,1,10,11)$ & -89.9606 \\
\hline $\mathrm{R}(5,6)$ & 1.3951 & $\mathrm{~A}(3,4,5)$ & 119.994 & $\mathrm{D}(2,1,10,12)$ & 90.0394 \\
\hline $\mathrm{R}(5,9)$ & 1.0998 & $\mathrm{~A}(3,4,8)$ & 119.9811 & $\mathrm{D}(6,1,10,11)$ & 90.0341 \\
\hline $\mathrm{R}(6,14)$ & 1.35 & $\mathrm{~A}(5,4,8)$ & 120.0249 & $\mathrm{D}(6,1,10,12)$ & -89.9659 \\
\hline $\mathrm{R}(10,11)$ & 1.07 & $\mathrm{~A}(4,5,6)$ & 120.0047 & $\mathrm{D}(1,2,3,4)$ & -0.0568 \\
\hline \multirow[t]{15}{*}{$\mathrm{R}(10,12)$} & 1.2584 & $\mathrm{~A}(4,5,9)$ & 120.0113 & $\mathrm{D}(1,2,3,7)$ & 179.9619 \\
\hline & & $\mathrm{A}(6,5,9)$ & 119.984 & $\mathrm{D}(13,2,3,4)$ & -179.9777 \\
\hline & & $\mathrm{A}(1,6,5)$ & 120.0 & $\mathrm{D}(13,2,3,7)$ & 0.041 \\
\hline & & $\mathrm{A}(1,6,14)$ & 120.008 & $\mathrm{D}(2,3,4,5)$ & 0.0341 \\
\hline & & $\mathrm{A}(5,6,14)$ & 119.992 & $\mathrm{D}(2,3,4,8)$ & -179.9964 \\
\hline & & $\mathrm{A}(1,10,11)$ & 119.8865 & $\mathrm{D}(7,3,4,5)$ & -179.9846 \\
\hline & & $\mathrm{A}(1,10,12)$ & 120.2269 & $\mathrm{D}(7,3,4,8)$ & -0.0151 \\
\hline & & $\mathrm{A}(11,10,12)$ & 119.8865 & $\mathrm{D}(3,4,5,6)$ & 0.0131 \\
\hline & & & & $\mathrm{D}(3,4,5,9)$ & -179.9995 \\
\hline & & & & $\mathrm{D}(8,4,5,6)$ & -179.9563 \\
\hline & & & & $\mathrm{D}(8,4,5,9)$ & 0.0311 \\
\hline & & & & $\mathrm{D}(4,5,6,1)$ & -0.0376 \\
\hline & & & & $\mathrm{D}(4,5,6,14)$ & 179.9881 \\
\hline & & & & $\mathrm{D}(9,5,6,1)$ & 179.975 \\
\hline & & & & $\mathrm{D}(9,5,6,14)$ & 0.0007 \\
\hline
\end{tabular}




\section{B. Vibrational Spectra}

A detailed study of Vibrational spectra has been carried out of the reported compound and its vibrational frequencies have been calculated using DFT-B3LYP level with 6-311+ $+G(d, p)$, there is a good agreement between the observed frequencies [10] and those calfulated by the DFT. A comparative chart is shown in Table-2 in which experimental values of IR ( $\mathrm{KBr}$ AND Nuzol), FTIR and laser Raman are displayed and simultaneously compared with the calculated values.

Table 2

Calculated Frequencies

\begin{tabular}{|c|c|c|c|}
\hline Mode & Frequency & Infrared & Raman Activity \\
\hline 1. & 89.29 & 0.0932 & 1.7407 \\
\hline 2. & 147.27 & 10.605 & 3.5035 \\
\hline 3. & 216.94 & 3.5404 & 4.1456 \\
\hline 4. & 227.12 & 4.0467 & 2.9963 \\
\hline 5. & 254.10 & 0.1540 & 1.8647 \\
\hline 6. & 288.30 & 6.0682 & 5.9608 \\
\hline 7. & 370.01 & 4.9874 & 13.9323 \\
\hline 8. & 423.92 & 33.1624 & 11.7099 \\
\hline 9. & 461.98 & 5.5853 & 8.1317 \\
\hline 10. & 531.37 & 0.0606 & 0.6337 \\
\hline 11. & 589.49 & 2.0756 & 21.0182 \\
\hline 12. & 613.75 & 2.3159 & 0.7831 \\
\hline 13. & 705.97 & 25.6381 & 5.1524 \\
\hline 14. & 781.36 & 42.3826 & 3.9844 \\
\hline 15. & 813.24 & 64.1729 & 8.8284 \\
\hline 16. & 860.71 & 56.7730 & 0.6167 \\
\hline 17. & 923.72 & 107.9414 & 8.2932 \\
\hline 18. & 968.90 & 2.3087 & 1.9129 \\
\hline 19. & 1056.37 & 4.8798 & 0.1656 \\
\hline 20. & 1090.56 & 0.1079 & 10.0093 \\
\hline 21. & 1096.07 & 0.5208 & 55.3954 \\
\hline 22. & 1191.18 & 13.4978 & 5.2519 \\
\hline 23. & 1225.10 & 150.8762 & 56.4407 \\
\hline 24. & 1243.49 & 20.4022 & 15.3639 \\
\hline 25. & 1320.79 & 11.8695 & 19.7427 \\
\hline 26. & 1338.04 & 10.9679 & 30.1950 \\
\hline 27. & 1462.33 & 63.1909 & 20.7026 \\
\hline 28. & 1473.89 & 21.1824 & 17.2158 \\
\hline 29. & 1514.20 & 111.6727 & 38.1445 \\
\hline 30. & 1585.65 & 147.4089 & 90.6789 \\
\hline 31. & 1637.24 & 153.8389 & 97.9203 \\
\hline 32. & 1707.41 & 273.3723 & 104.0877 \\
\hline
\end{tabular}


S. K. Tyagi et al Int J Sci Res Sci \& Technol. November-December-2021, 8 (6) : 481-483

\begin{tabular}{|l|l|c|c|}
\hline 33. & 3021.00 & 87.2039 & 155.9042 \\
\hline 34. & 3229.41 & 1.7549 & 139.9645 \\
\hline 35. & 3248.08 & 0.0788 & 129.0763 \\
\hline 36. & 3253.63 & 0.5832 & 361.2170 \\
\hline
\end{tabular}

The corresponding curves of Infrared and Raman activities are shown in Fig. 2 and 3.

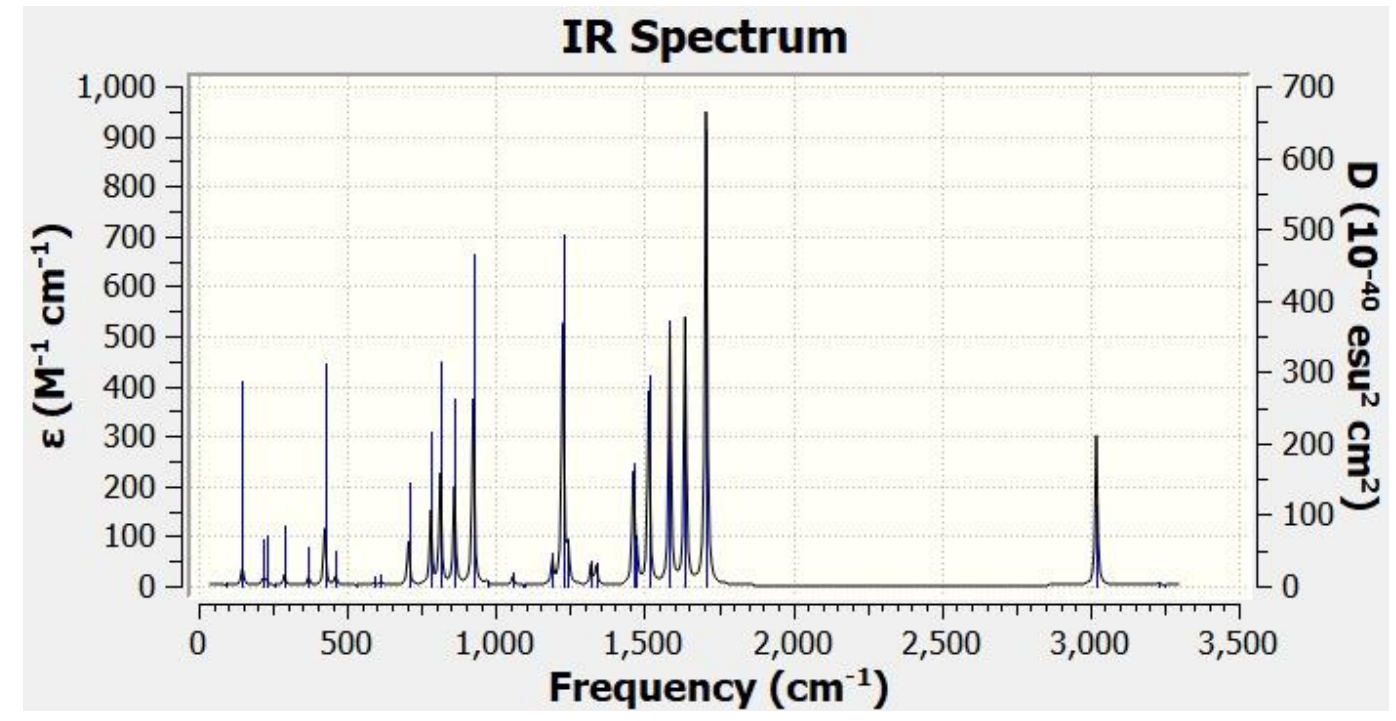

Figure 2

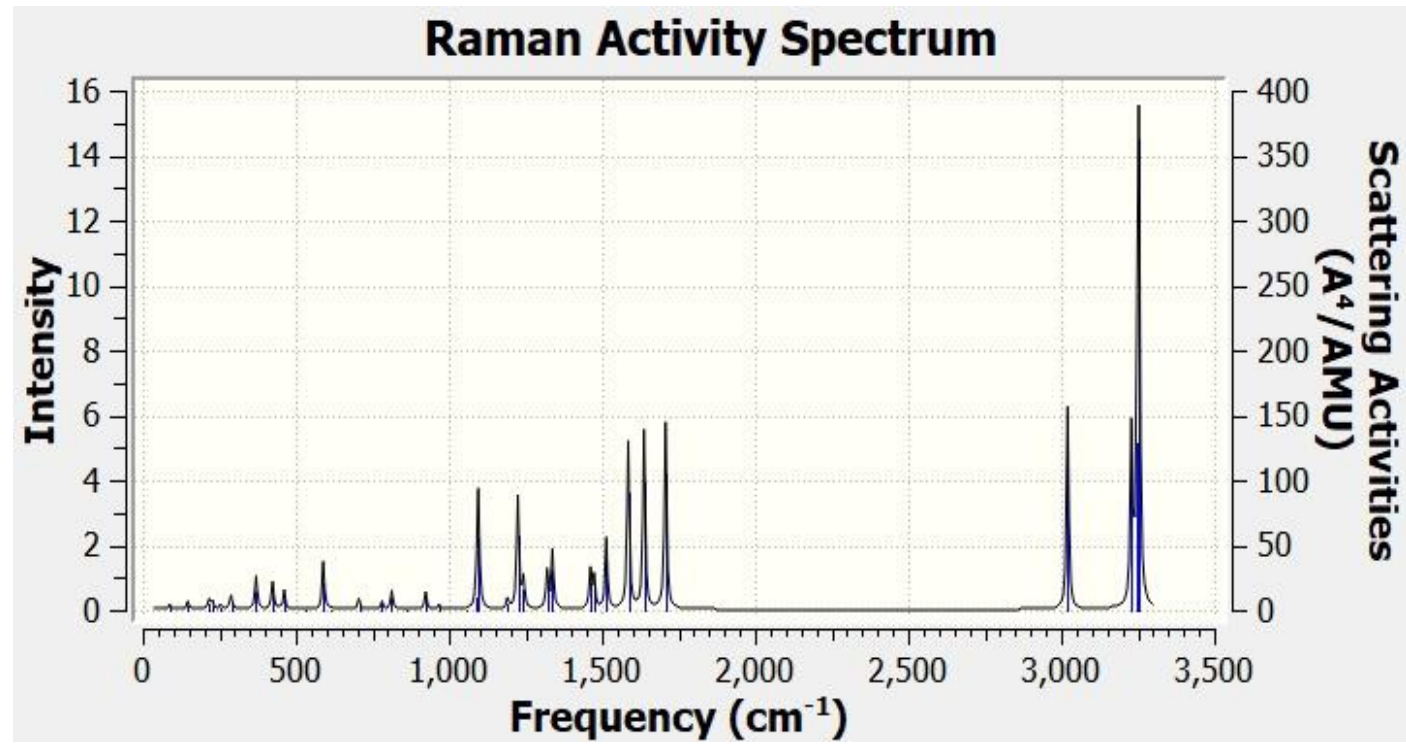

Figure 3

The results obtained by the DFT calculations are in accordance with the experimental results obtained for substituted benzaldehydes as shown by several researchers time to time.[8-11]

\section{Theromodynamic Properties}

Theoretical geometrical parameters represent a good approximation and they are the basis for calculating vibrational frequencies and thermodynamic parameters. The frequency calculations compute the zero point energies, thermal correction to internal energy and entropy as well as the heat capacity for a molecular system. 
S. K. Tyagi et al Int J Sci Res Sci \& Technol. November-December-2021, 8 (6) : 481-483

These functions describe the thermodynamic stability of the system at the given conditions of pressure and temperature.

Table 3: Calculated values of 2,6CFB thermodynamic functions by frequency calculations

\begin{tabular}{|c|c|}
\hline Thermodynamic Functions & Value \\
\hline Zero-point correction & 0.093314 (Hartree/Particle) \\
\hline Thermal correction to Energy & 0.101516 \\
\hline Thermal correction to Enthalpy & 0.102460 \\
\hline Thermal correction to Gibbs Free Energy & 0.059498 \\
\hline Sum of electronic and zero-point Energies & -899.666315 \\
\hline Sum of electronic and thermal Energies & -899.658113 \\
\hline Sum of electronic and thermal Enthalpies & -899.657169 \\
\hline Sum of electronic and thermal Free Energies & -899.700131 \\
\hline
\end{tabular}

Table 4: Thermodynamic properties of 2,6CFB as calculated BY DFT/B3LYP/6-311 G (d,p) level basis set

\begin{tabular}{|c|c|c|c|}
\hline & $\begin{array}{c}\text { E (Thermal) } \\
\text { KCal/Mol }\end{array}$ & $\begin{array}{c}\text { CV } \\
\text { Cal/Mol-Kelvin }\end{array}$ & $\begin{array}{c}\text { S } \\
\text { Cal/Mol-Kelvin }\end{array}$ \\
\hline Total & 63.702 & 30.096 & 90.421 \\
\hline Electronic & 0.000 & 0.000 & 0.000 \\
\hline Translational & 0.889 & 2.981 & 41.081 \\
\hline Rotational & 0.889 & 2.981 & 30.141 \\
\hline Vibrational & 61.925 & 24.134 & 19.198 \\
\hline Vibration 1 & 0.602 & 1.957 & 3.681 \\
\hline Vibration 2 & 0.617 & 1.906 & 2.707 \\
\hline Vibration 3 & 0.646 & 1.815 & 1.985 \\
\hline Vibration 4 & 0.651 & 1.800 & 1.902 \\
\hline Vibration 5 & 0.665 & 1.756 & 1.702 \\
\hline Vibration 6 & 0.685 & 1.696 & 1.484 \\
\hline Vibration 7 & 0.742 & 1.534 & 0.879 \\
\hline Vibration 8 & 0.786 & 1.418 & 0.760 \\
\hline Vibration 9 & 0.820 & 1.334 & 0.584 \\
\hline Vibration 10 & 0.886 & 1.181 & 0.468 \\
\hline Vibration 11 & 0.947 & 1.054 & 0.427 \\
\hline Vibration 12 & 0.973 & 1.003 & \\
\hline
\end{tabular}

\section{Electric Moments}

The dipolemoment in a melocule is a important property that is mainly used to study the intermolecular interactions involving the nonbonded type dipole-dipole interactions, as we know that higher the dipolemoment, stronger will be the intermolecular interactions. In the absence of experimental data, the values 
of polarizability and hyperpolarizability calculated at the same level of theory and the same basis set for the compound 2,6-CFB can provide a satisfactory comparison of these quantities.

$$
\begin{aligned}
& \mu=\left(\mu_{x}^{2}+\mu_{y}^{2}+\mu_{z}^{2}\right)^{1 / 2} \\
& \alpha=\frac{1}{3}\left(\alpha_{x x}+\alpha_{y y}+\alpha_{z z}\right) \\
& \Delta \alpha=\frac{1}{\sqrt{2}}\left[\left(\alpha_{x x}-\alpha_{y y}\right)^{2}+\left(\alpha_{y y}-\alpha_{z z}\right)^{2}+\left(\alpha_{z z}-\alpha_{x x}\right)^{2}+6 \alpha_{x z}^{2}\right]^{1 / 2}
\end{aligned}
$$

First order polarizability $\beta=\left[\left(\beta_{x x x}+\beta_{x y y}+\beta_{x z z}\right)^{2}+\left(\beta_{y y y}+\beta_{x x y}+\beta_{y z z}\right)^{2}+\left(\beta_{z z z}+\beta_{x x z}+\beta_{y y z}\right)^{2}\right]^{1 / 2}$

Table 4 Represents the value of dipole moment polarizability and hyperpolarizability for the mentioned compound

Table 4

\begin{tabular}{|c|c|c|c|c|c|}
\hline \multicolumn{2}{|c|}{ Dipole moment } & \multicolumn{2}{c|}{ Polarizability } & \multicolumn{2}{c|}{ Hyperpolarizability } \\
\hline$\mu_{\mathrm{x}}$ & -1.2201 & $\alpha_{\mathrm{xx}}$ & -67.3700 & $\beta_{\mathrm{xxx}}$ & 11.6927 \\
\hline$\mu_{\mathrm{y}}$ & -5.1620 & $\alpha_{\mathrm{yy}}$ & -58.2306 & $\beta_{\mathrm{yyy}}$ & -36.4569 \\
\hline$\mu_{\mathrm{z}}$ & -0.0008 & $\alpha_{\mathrm{zz}}$ & -64.6266 & $\beta_{\mathrm{zzz}}$ & -0.0021 \\
\hline & & $\alpha_{\mathrm{xy}}$ & -6.2761 & $\beta_{\mathrm{xxy}}$ & -16.7592 \\
\hline & & $\alpha_{\mathrm{xz}}$ & -0.0041 & $\beta_{\mathrm{xxz}}$ & -0.0018 \\
\hline & & $\alpha_{\mathrm{yz}}$ & -0.0084 & $\beta_{\mathrm{xyy}}$ & -9.1817 \\
\hline & & & & $\beta_{\mathrm{xyz}}$ & -0.0051 \\
\hline & & & & $\beta_{\mathrm{xzz}}$ & 7.3464 \\
\hline & & & & $\beta_{\mathrm{yyz}}$ & -0.0006 \\
\hline
\end{tabular}

\section{E. HOMO-LUMO Band Gap}

Using the values of dipole moment, polarizability and The molecules which are conjugated can be hyperpolarizability from table 4 , we get the values $\mu, \alpha, \Delta \alpha$ and $\beta$ as following.

distinguished on the basis of frontier molecular orbits and can be well explained by the separation between these orbits, the highest occupied molecular orbital

$\mu=5.3042$ (HOMO) and lowest unoccupied molecular orbital $\alpha=-63.4090$

$\Delta \alpha=8.12414$

$\beta=44.4552$ (LUMO), the separation between these orbitals provide the stability of the molecule which in turn provides significant degree of intramolecular charge transfer from the end-capping electron-donor groups through $\mathrm{P}$-conjugated path. Through $\mathrm{P}$-conjugated bridge the strong charge transfer interaction results in 
substantial ground state donor-acceptor mixing and the emergence of a charge transfer band in the electronic absorption spectrum of a charge transfer band in the electronic absorption spectrum.. The wave function analysis shows that the electron absorption corresponds to the transition from the ground state to the first exited state and is mainly described by one-electron excitation from the HOMO to LUMO. The HOMO and LUMO energies of the reported compound 2,6CFB have been calculated at B3LYP/6-31G (d,p) level. Figures 4 and 5 shows HOMO and LUMO respectively. The HOMO and LUMO energies thus obtained from DFT calculations are -0.26095 a.u. and -0.08002 a.u. respectively and the energy difference between HOMO and LUMO is 0.18093 a.u. which indicates fairly high stability of molecule.

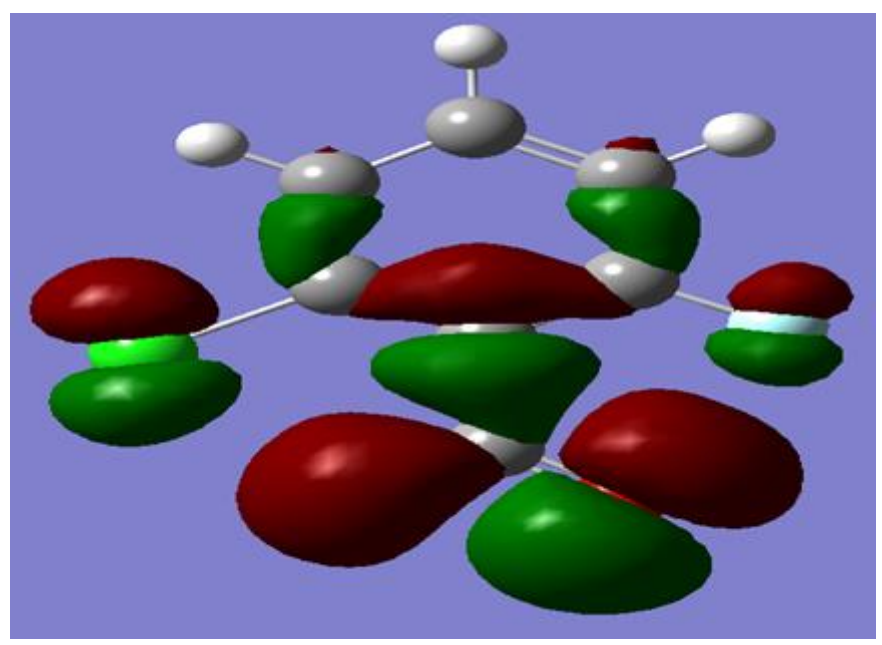

Figure 4

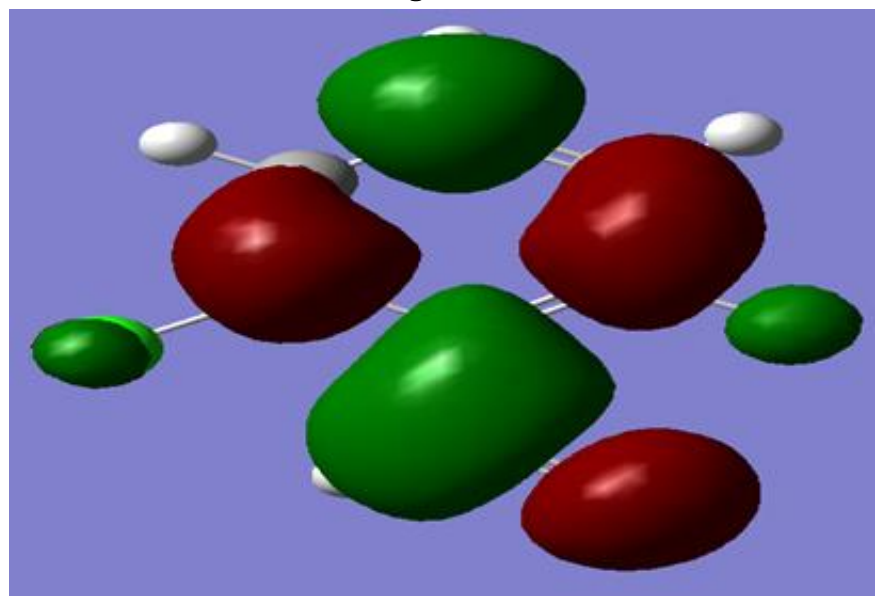

Figure 5

\section{CONCULUSION}

In the present work we have calculated the geometrical parameters, vibrational frequencies, frontier molecular orbitals and NLO properties of 2,6CFB by using Becke-3Lee-Yang-Parr(B3LYP) functional supplemented with the standard 6$31 \mathrm{G}(\mathrm{d}, \mathrm{p})$. We have also calculated thermodynamic properties of the mentioned compound at different temperatures along with dipolemoment, polarizability and hyperpolarizability. The HOMO-LUMO energy gap predicts the greater stability of the compound.

\section{REFERENCES}

[1]. A. Nataraj, V. Balachandran, T. Karthick, J. Mol. Struct. 1006 (2011) 104-112.

[2]. S. Takeuchi, M. Kochi, K. Sakaguchi, K. Nakagawa, T. Mizutani, Agric. Biol. Chem. 42 (1978) 1449.)

[3]. Takao Itoh, J. Mol. Struct. 786 (1) (2006) 39.

[4]. T.G. Strand, M.A. Tafipolsky, L.V. Vilkov, H.V. Volden, J. Mol. Struct. 443 (1-3) (1998) 9.

[5]. E. Bock, E. Tomchuk, Can. J. Chem. 50 (1972) 2890.

[6]. Peter D.J. Anderson, M. Tereza Fernandez, Gabriella Pocsfalvi, Rod S. Mason, J. Chem. Soc. Perkin Trans. 2 (1997) 873

[7]. Gaussian 09, Revision D.01, M. J. Frisch, G. W. Trucks et al.

[8]. B.S. Yadav, S.K. Tyagi, M.K. Yadav, Material Science Research India Vol 3 (2) (2005), 203

[9]. B.S.Yadav,Vibha Sharma,Sachin Kumar, International Journal of Engineering Science Invention (IJESI) ISSN (Online): 2319 - 6734, ISSN (Print): 2319 - 6726 www.ijesi.org ||Volume 7 Issue 12 Ver I || Dec 2018 || PP 0915

[10]. B.S.Yadav,Vibha Sharma,Sachin Kumar, 2018 IJSRST | Volume 4 | Issue 11 | Print ISSN: 23956011 | Online ISSN: 2395-602X Themed 
Section: Science and Technology DOI : https://doi.org/10.32628/IJSRST18401165

[11]. Seema, B.S.Yadav, Sachin Kumar, International Journal for Research in Engineering Application \& Management (IJREAM) ISSN : 2454-9150 Vol-05, Issue-02, May 2019

[12]. Seema, B.S.Yadav, Sachin Kumar, Volume 10 Number 07 July 2019, Universal Review Scientific Information and Technological Board of Sadhana

\section{Cite this article as :}

S. K. Tyagi, Sachin Kumar, "Molecular Structure, Vibrational Spectral Studies, NLO Properties and frontier molecular investigations of 2-Chloro-6Fluoro Benzaldehyde by DFT", International Journal of Scientific Research in Science and Technology (IJSRST), Online ISSN : 2395-602X, Print ISSN : 23956011, Volume 8 Issue 6, pp. 481-483, NovemberDecember 2021. Available at doi $\quad$ : https://doi.org/10.32628/IJSRST218671

Journal URL : https://ijsrst.com/IJSRST218671 